\title{
Primordial soup or vinaigrette: did the RNA world evolve at acidic pH?
}

\author{
Harold S Bernhardt ${ }^{*}$ and Warren P Tate
}

\begin{abstract}
Background: The RNA world concept has wide, though certainly not unanimous, support within the origin-of-life scientific community. One view is that life may have emerged as early as the Hadean Eon 4.3-3.8 billion years ago with an atmosphere of high $\mathrm{CO}_{2}$ producing an acidic ocean of the order of $\mathrm{pH}$ 3.5-6. Compatible with this scenario is the intriguing proposal that life arose within alkaline $(\mathrm{pH}$ 9-11) deep-sea hydrothermal vents like those of the 'Lost City', with the interface with the acidic ocean creating a proton gradient sufficient to drive the first metabolism. However, RNA is most stable at $\mathrm{pH} 4-5$ and is unstable at alkaline $\mathrm{pH}$, raising the possibility that RNA may have first arisen in the acidic ocean itself (possibly near an acidic hydrothermal vent), acidic volcanic lake or comet pond. As the Hadean Eon progressed, the ocean $\mathrm{pH}$ is inferred to have gradually risen to near neutral as atmospheric $\mathrm{CO}_{2}$ levels decreased.
\end{abstract}

Presentation of the hypothesis: We propose that RNA is well suited for a world evolving at acidic pH. This is supported by the enhanced stability at acidic pH of not only the RNA phosphodiester bond but also of the aminoacyl-(t)RNA and peptide bonds. Examples of in vitro-selected ribozymes with activities at acid pH have recently been documented. The subsequent transition to a DNA genome could have been partly driven by the gradual rise in ocean $\mathrm{pH}$, since DNA has greater stability than RNA at alkaline $\mathrm{pH}$, but not at acidic $\mathrm{pH}$.

Testing the hypothesis: We have proposed mechanisms for two key RNA world activities that are compatible with an acidic milieu: (i) non-enzymatic RNA replication of a hemi-protonated cytosine-rich oligonucleotide, and (ii) specific aminoacylation of tRNA/hairpins through triple helix interactions between the helical aminoacyl stem and a single-stranded aminoacylating ribozyme.

Implications of the hypothesis: Our hypothesis casts doubt on the hypothesis that RNA evolved in the vicinity of alkaline hydrothermal vents. The ability of RNA to form protonated base pairs and triples at acidic pH suggests that standard base pairing may not have been a dominant requirement of the early RNA world.

Reviewers: This article was reviewed by Eugene Koonin, Anthony Poole and Charles Carter (nominated by David Ardell).

Keywords: RNA world, evolution, acidic pH, protonated base pairs, RNA triple helix, tRNA

\section{Background}

The concept of an RNA world - an early stage of evolution where RNA functioned as both gene and catalyst has wide, though certainly not unanimous, support among those who study the origin of life. However, any such evolutionary model needs to be firmly rooted in an understanding of likely primordial physical and chemical Earth conditions [1]. The hypothesis that life may have

\footnotetext{
* Correspondence: harold.bernhardt@otago.ac.nz

Department of Biochemistry, University of Otago, P.O. Box 56, Dunedin, New
} Zealand

\section{Biomed Central}

emerged during the Hadean Eon 4.3-3.8 billion years ago [2] is supported by the discovery of zircon crystals that suggest the presence of liquid water and continental crust on the Earth as early as 4.4 billion years ago, or within 150 million years of the Earth's formation [3]. A projected high level of atmospheric $\mathrm{CO}_{2}$ is proposed to have produced an acidic ocean of the order of $\mathrm{pH} 3.5-6$ $[4,5]$ (for the purpose of our hypothesis we have chosen $\mathrm{pH} 4-5$ as acceptable mid-range values). The $\mathrm{pH}$ is inferred to have subsequently risen to $\sim 6.8$ as $\mathrm{CO}_{2}$ levels gradually decreased during the Hadean Eon; in parallel, 
the ocean temperature may have dropped from $~ 100$ to $\sim 70^{\circ} \mathrm{C}$ [5]. Alternatively, air and ocean temperatures may have become clement soon after the Earth's formation $[6,7]$.

Michael Russell and colleagues have proposed that life arose within alkaline ( $\mathrm{pH}$ 9-11) deep-sea hydrothermal vents similar to those of the Lost City [8,9], with the interface with the acidic ocean forming iron sulfide structures that functioned as proto-membranes, across which a proton gradient occurred sufficient to drive the first metabolism (see also [6]). However, one difficulty with this attractive scenario is the instability of the phosphodiester bond of RNA at alkaline pH [10] (Figure 1), suggesting that RNA is more likely to have evolved in an environment of lower $\mathrm{pH}$. Indeed a number of investigators in simulated experiments have isolated in vitro-selected ribozymes with activity at acid $\mathrm{pH}$ (sometimes optimal), and have suggested as a result that the RNA world may have evolved in such an acidic milieu, for example Jayasena and Gold [11]:

"An infinite number of conditions may be chosen to explore the versatility of RNA for catalysis, and to that list one must now add low $\mathrm{pH}$... The prebiotic "RNA world" may have been more robust than is suggested by the limited reactions catalyzed thus far by RNAs under rather more standard laboratory conditions" [11].

Similarly, Burke and Hoffman [12] point out that their discovery of an RNA that binds coenzyme A and other adenosine analogues with a $\mathrm{pH}$ optimum of 5 , suggests that such harsh conditions may be compatible with those existing in an RNA world. Echoing Jayasena and Gold, they argue that this makes the RNA world theory

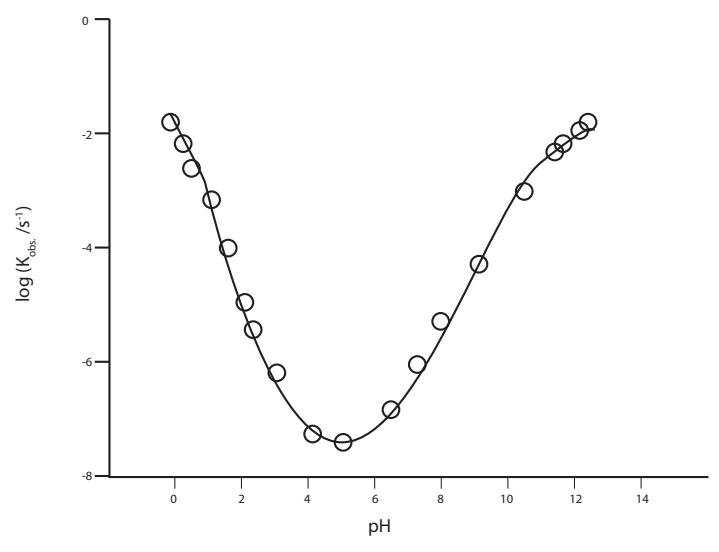

Figure 1 The RNA phosphodiester bond is most stable at pH 4-5 at $90^{\circ} \mathrm{C}$. Hydrolysis of the dinucleoside $3^{\prime}, 5^{\prime}-\mathrm{UpU}$ at $90^{\circ} \mathrm{C}$ as a function of $\mathrm{pH}$. Figure reprinted with permission from [15] Oivanen et al. ${ }^{\circledR} 1998$ American Chemical Society; data used with permission from [10] Järvinen et al. ${ }^{\circledR} 1991$ American Chemical Society. more robust than if the supporting evidence came only from mild laboratory conditions. Miyamoto and colleagues [13] note that acidic seawater or acidic clay layers are included in discussions of possible environments on the prebiotic Earth, and that depurination of deoxyribonucleosides occurs at acid $\mathrm{pH}$, making DNA more labile than RNA under these conditions. They suggest that a first step in developing a self-replicating RNA might have been a ligase ribozyme functional in acidic conditions, similar to the one they isolated by in vitro selection $[13,14]$.

The following observations are consistent with the hypothesis that the RNA world was compatible with an acidic $\mathrm{pH}$ environment. The supporting observations are presented according to their proposed occurrence chronologically, in parallel with a proposed gradual increase in $\mathrm{pH}$ (Figure 2).

\section{The phosphodiester bond of RNA is most stable at pH 4- 5 at $90^{\circ} \mathrm{C}$}

RNA is susceptible to alkaline hydrolysis at $\mathrm{pH}>6$, whereas, in contrast, acid hydrolysis only occurs at $\mathrm{pH}<$ 2 [15]. As shown in Figure 1, Järvinen and colleagues [10] found that the rate of phosphodiester bond hydrolysis within the RNA dinucleoside $3^{\prime}, 5^{\prime}-\mathrm{UpU}$ is lowest at $\mathrm{pH} 4-5$ at $90^{\circ} \mathrm{C}$, especially relevant to models that propose a hot Hadean ocean [5]. Prior to the emergence of coded protein synthesis - and the evolution of proteins able to bind to and protect RNA - an acidic environment may have conferred stability to RNA necessary for its evolution.

\section{Ribozymes with maximal activity at acidic $\mathrm{pH}$ have been isolated by in vitro selection}

A number of ribozymes with a range of catalytic activities have been isolated by in vitro selection at acidic $\mathrm{pH}$. In some ways this is not surprising, as the RNA bases $\mathrm{A}, \mathrm{C}$ and $\mathrm{G}$ have $p K_{\mathrm{a}} \mathrm{s}$ between 2 and 4 , and so catalytic activity utilising this ionization could be expected at low $\mathrm{pH}$. Ribozymes active at acidic $\mathrm{pH}$ sometimes maximally - catalyse RNA ligation $[13,14,16]$, self-cleavage [11] (Figure 3) and amino acid-activation (similar to the synthesis of aminoacyladenylates by modern protein aminoacyl-tRNA synthetases) [17]. This is a limited number of activities but all would have been important in the context of an RNA world. As discussed, Miyamoto and colleagues have argued that RNA ligation may have been a forerunner to self-replication [13].

\section{The aminoacyl-tRNA bond is more stable at acidic pH}

The ease with which ribozymes able to catalyze selfaminoacylation or aminoacylation in trans have been isolated by in vitro selection suggests this is a reaction 


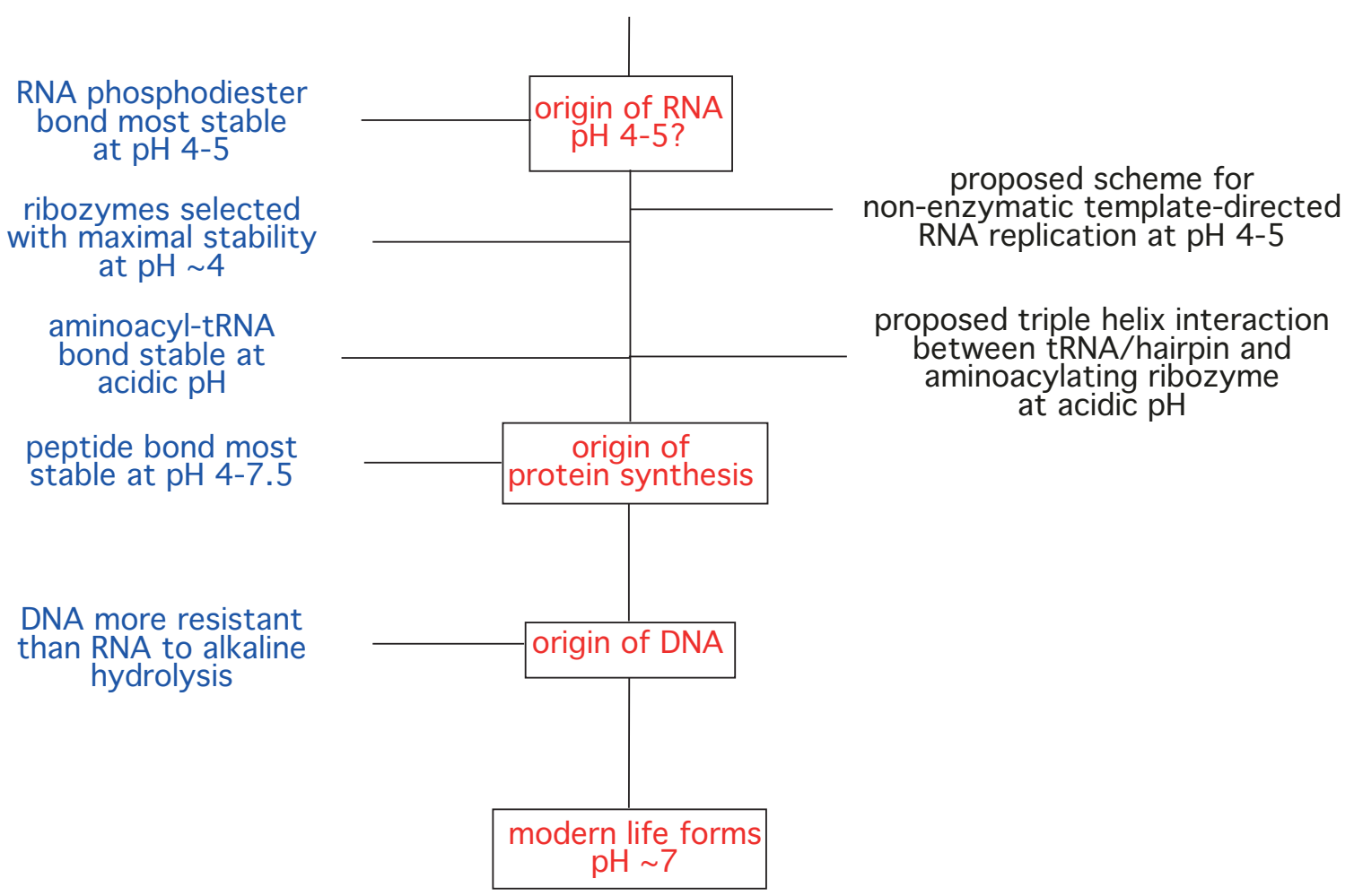

Figure 2 Proposed timeline of early evolution from the origin of RNA ( $\mathrm{pH} \mathrm{4-5)} \mathrm{to} \mathrm{modern} \mathrm{life} \mathrm{forms} \mathrm{(pH} 7$ ). On the right of diagram are two proposed RNA world mechanisms compatible with acidic pH (see section 'Testing the hypothesis' for details).

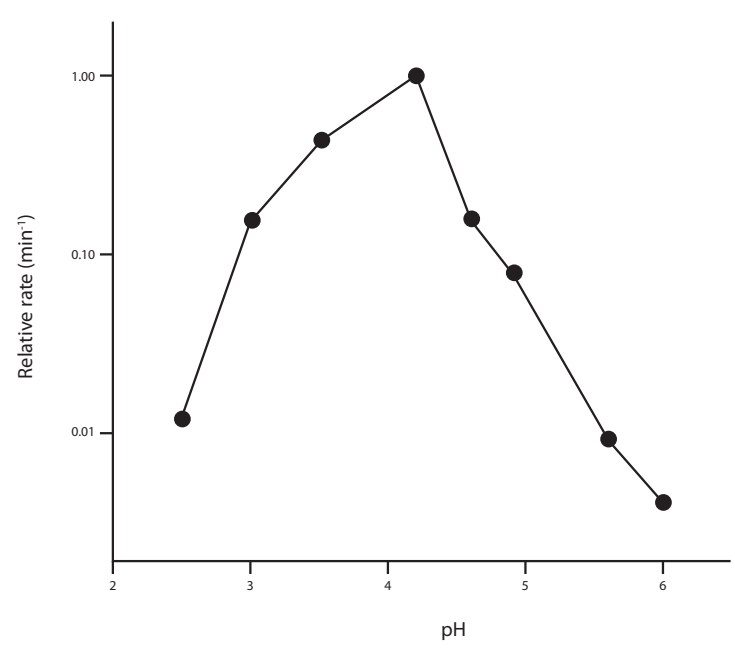

Figure 3 A self-cleaving ribozyme isolated by in vitro-selection has maximal activity at $\mathbf{p H}$ 4.2. The rate of cleavage obtained at each $\mathrm{pH}$ value was normalized to the maximum rate measured at $\mathrm{pH}$ 4.2. Figure adapted with permission from [11] Jayasena and Gold $1997^{\circledR} 1997$ National Academy of Sciences, U.S.A. at which RNA is particularly adept [18], and therefore promiscuous aminoacylation was likely a hallmark of the RNA world. If so, this was fortunate, as aminoacylation of tRNA - and the hairpin precursor from which it is thought to have evolved $[19,20]$ - was probably essential for the evolution of coded ribosomal protein synthesis [21]. However, the mixed phosphate anhydride bond of aminoacyl-tRNA is particularly unstable at neutral and alkaline $\mathrm{pH}[22,23]$. This is not the case at acidic $\mathrm{pH}$; as illustrated in Figure 4 by the hydrolysis of leucyl-tRNA as a function of $\mathrm{pH}$, the rate of hydrolysis decreases with decreasing $\mathrm{pH}$ from $\mathrm{pH} 11$ to 6 the lowest value measured [22]. Because of the greater stability of this bond at acidic $\mathrm{pH}$, typically aminoacylated tRNAs are purified at $\mathrm{pH} 4.5$ (U. Varshney, pers. commun.) and analyzed by PAGE at pH 5 [24]. Stabilization of the aminoacyl-RNA bond would have been critical to the early evolution of coded protein synthesis, as unlike in the modern system, there would have been no protection of this bond by the protein elongation factor EF-Tu, which transports aminoacyl-tRNA to the ribosome [25]. 


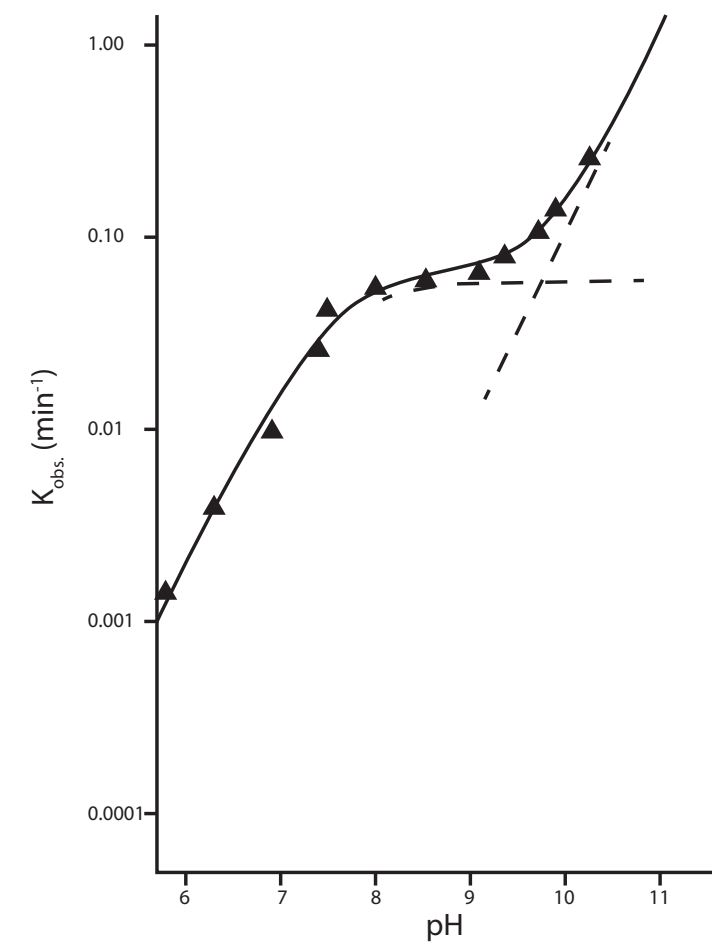

Figure 4 Rate of hydrolysis of aminoacyl-tRNA decreases with $\mathrm{pH}$ over the range $\mathrm{pH}$ 6-11. Rate of hydrolysis of leucyl-tRNA at $37^{\circ} \mathrm{C}$ and ionic strength 0.30 (the break in the curve between $\mathrm{pH} 8$ 10 represents the shift from rate-determining hydroxide attack on the ammonium acid ester cation to rate-determining attack on the free amino acid ester). Figure adapted with permission from [22] Wolfenden ${ }^{\circledR} 1963$ American Chemical Society.

The peptide bond is most stable over the range $\mathrm{pH}$ 4-7.5 Pascal and colleagues [26] have calculated the theoretical influence of $\mathrm{pH}$ on the ratio of equilibrium constants for peptide bond formation. Perhaps surprisingly, the results indicate that the peptide bond is stable over the range $\mathrm{pH}$ 4-7.5, with optimum stability at $\mathrm{pH}$ 6. This is consistent with our current understanding that protein synthesis arose within the RNA world, which, according to our hypothesis, would have been when conditions were still relatively acidic (see Figure 2).

DNA is more resistant than RNA to alkaline hydrolysis While RNA is prone to alkaline hydrolysis at $\mathrm{pH}>6$ [15], the 2'-deoxy sugar of the DNA backbone is much more resistant [27]. The presence of the vicinal 2',3'hydroxyl groups on the ribose of RNA means that alkaline hydrolysis proceeds via the formation of an intermediate cyclic 2',3'-phosphonucleoside, whereas deoxyribose lacks the 2'-OH group required to form this intermediate. It is possible that the rise in ocean $\mathrm{pH}$ as the Hadean Eon progressed was partly responsible for driving the transition from an RNA to a DNA genome. The greater stability of the peptide bond [26] compared with DNA [13] at acidic pH supports the conjecture that proteins evolved before DNA [28].

\section{Presentation of the hypothesis}

We propose that the RNA world evolved in an acidic milieu. Stability was critical for evolution: the central tenet of our hypothesis is that chemical identities, including molecular species and bonding interactions, require stability in order for evolution to take place. The fundamental importance of stability can be seen in the core structure of RNA, where it is possible that base pair interactions afforded nucleotide bases within the interior of double-stranded helical regions protection against chemical attack; RNA hairpins are remarkably stable in comparison with single-stranded RNA

[29]. An acidic environment would have further increased the stability of RNA and therefore the chances for its evolution. Likewise, acidic $\mathrm{pH}$ would have enhanced the half-life of the aminoacyl-(t)RNA bond, increasing the chances for the evolution of protein synthesis.

\section{Discussion}

These ideas were first presented by HSB at ISSOL 2011 in Montpellier France. At this conference, Jeremy Kua (Kua and Bada, 2011; [30]) presented complementary work on the stability of RNA drawn from a comparative analysis of published data of the stability of (i) the ribose sugar, (ii) cytosine pyrimidine base, and (iii) the phosphodiester bond, for various environments proposed for the origin of life ( $\mathrm{pH} 3.5-10)$. This included both acidic and alkaline hydrothermal vents and an acidic ocean. They concluded from this analysis that RNA has maximum stability at $0^{\circ} \mathrm{C}$ at $\mathrm{pH} 5.5$ and at $75^{\circ} \mathrm{C}$ at $\mathrm{pH} 5$ [30], consistent with our findings.

Further support for the hypothesis comes from recent work carried out by Perez-Jimenez and colleagues [31], who used phylogenetic analysis to infer the sequences of thioredoxin protein enzymes from extinct organisms. When produced in the laboratory, the 'oldest' of the reconstructed enzymes - proposed to date back 4 billion years - have considerably higher activity at pH 5 than their modern counterparts. Although their results throw light on the environment during the early evolution of proteins (supporting our hypothesis that this occurred during the Hadean Eon) as opposed to the RNA world, their findings are consistent with our proposal that conditions at this later time were still relatively acidic (see Figure 2). In contemporary systems, thioredoxin is both an intracellular and secreted protein [32]. If this were also the situation during the early evolution of 
thioredoxin, it suggests that both the external and intracellular environment were more acidic at this time 4 billion years ago than they are today [31]. This is possible if at the time thioredoxin evolved the cell membrane was much 'leakier' than today, and was therefore an imperfect barrier to protons. A useful comparison can be made with the acidophilic eubacterium Acetobacter aceti ( $A$. aceti) that converts ethanol in wine into acetic acid in the industrial production of vinegar and can function with an intracellular $\mathrm{pH}$ as low as 3.9 [33]. Because of the high membrane-permeability of acetic acid, $A$. aceti has limited ability to maintain its internal $\mathrm{pH}$ and so at times experiences the most acidic cytoplasmic $\mathrm{pH}$ of any known organism: when grown on ethanol, the external $\mathrm{pH}$ and internal $\mathrm{pH}$ decrease in parallel from 6.2 to 3.5 and from 5.8 to 3.9 , respectively [33]. In view of the probable close relationship between external and intracellular $\mathrm{pH}$ in the early evolution of life, the greater stability at acid $\mathrm{pH}$ of RNA and key RNA bonds utilized in modern biology supports our hypothesis that (membrane-encapsulated) RNA world evolution took place in an acidic environment.

\section{Testing the hypothesis}

The following two proposed RNA world activities are compatible with an acidic milieu, and are open to experimental testing. While not proving the hypothesis, demonstration of the feasibility of either or both of these mechanisms (and the acidic conditions required) would give added weight to our proposal of an RNA world evolving at acidic $\mathrm{pH}$ (see Figure 2 for a possible chronology of the proposed mechanisms).

\section{A possible scheme for non-enzymatic template-directed RNA replication at $\mathrm{pH}$ 4-5}

Prior to the emergence of an RNA replicase, non-enzymatic replication of shorter sequences of RNA may have occurred. It has proven difficult to find a pair of complementary oligonucleotides each of which will act as an efficient template for the other, allowing repeated amplification of the two sequences [34]. Work in this area has focused on $\mathrm{C}$-rich sequences such as the RNA oligonucleotide CCGCC [35] and DNA oligonucleotide $(\mathrm{CCCG})_{3} \mathrm{CC}$ [36], which make particularly good templates (this work has used the activated RNA nucleotide analogues 5'-phosphoro (2-methyl)-imidazolides, which unlike standard RNA nucleotides - undergo efficient and regiospecific template-directed incorporation into a copy strand). At neutral $\mathrm{pH}$ however, C-rich sequences produce G-rich copies that tend to form higher-order structures that inhibit further replication [34]. Non-standard base pair interactions that can occur at acidic $\mathrm{pH}$ suggest a possible solution to this dilemma. As shown in Figure 5a, Escherichia coli (E. coli) tRNA ${ }^{\text {Gly(GCC) }}$ a

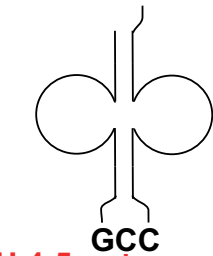

pH 4-5

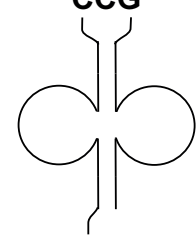

b

GCCGCCGCCGCC $? \mathrm{pH} \mathrm{4-5}$ GCCGCCGCCGCC

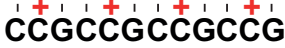

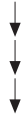

Figure 5 A possible scheme for non-enzymatic RNA replication at pH 4-5. (a) tRNA ${ }^{\text {Gly(GCC) }}$ forms dimers through its GCC anticodon due to hemi-protonation of the central cytosine at $\mathrm{pH} 4-5$ [37](b) At $\mathrm{pH}$ 4-5, C-rich $(\mathrm{GCC})_{n}$ sequences might produce C-rich duplicates by non-enzymatic replication. Base pairs involving hemi-protonated cytosines are indicated by (+).

forms dimers through its quasi-self complementary GCC anticodon, but only at $\mathrm{pH}$ 4-5 [37]. Romby and colleagues proposed that, at this acidic $\mathrm{pH}$, the GCC anticodon is able to self-pair through the sharing of a proton between the two central cytosines, forming a C$\mathrm{C}(+)$ hemi-protonated base pair. It would therefore appear possible that, as illustrated in Figure 5b, hemiprotonated linear GCC repeat sequences could serve as templates to produce identical copies at $\mathrm{pH}$ 4-5. If so, this might have provided a mechanism for successful non-enzymatic replication at the dawn of the RNA world, as both template and copy strands are similarly (equally) C-rich. DNA sequences consisting of GCC repeats form hairpins even at neutral $\mathrm{pH}$ [38], and these should be stabilized in acidic conditions by protonated $\mathrm{C}-\mathrm{C}(+)$ base pairs (RNA hairpins probably played an important role in the early evolution of the RNA world due to their resistance to thermal and chemical degradation). Similarly, formation of protonated $\mathrm{C}-\mathrm{A}(+)$ base pairs at acidic $\mathrm{pH}$ [39-43] suggests that RNA sequences consisting of GCC repeats might also template GAC repeat sequences or mixed $\mathrm{GCC} / \mathrm{GAC}$ sequences under these conditions.

\section{A mechanism for specific aminoacylation of RNA hairpins and ancestral tRNA}

With an RNA world at acidic $\mathrm{pH}$, a possible mechanism for the specific aminoacylation of tRNA (and its hairpin precursor $[19,20])$ can be suggested. Modern protein aminoacyl-tRNA synthetases achieve specificity through recognition of particular sequences of nucleotides in the tRNA aminoacyl stem adjacent to the 3' CCA terminus where the amino acid is attached, which has been 
termed the RNA operational code [44]. Di Giulio has proposed that tRNA arose by the duplication and ligation of a hairpin approximately half the length of the contemporary tRNA molecule [19]. Due to the symmetry of base pair interactions, the RNA operational code in tRNA would also have been present in the precursor hairpin, and conserved in the transition from hairpin to tRNA [20]. Prior to the evolution of coded protein synthesis in the RNA world, aminoacylation would have been catalyzed by ribozymes. Recognition of the RNA operational code nucleotides by modern protein synthetases is through the interaction of these nucleotides with specific amino acid residues. Recognition by a ribozymal synthetase could have instead been through either (i) tertiary interactions, (ii) base pairing between ribozymal nucleotides and nucleotides of the operational RNA code following strand-separation of the tRNA/hairpin aminoacyl stem, or (iii) formation of a base pair-specific triple-helix interaction with the tRNA/hairpin aminoacyl stem, which includes the RNA operational code nucleotides. Such a pyrimidine triple helix - pyrimidine-purinepyrimidine, with the Watson-Crick helix in italics - only forms at acidic $\mathrm{pH}$, with the third polypyrimidine strand forming parallel Hoogsteen interactions with the polypurine strand within the major groove of the WatsonCrick double helix ([45]; see also [46]). Thermal dissociation studies have shown that, in DNA triple helixes at least, a single purine-pyrimidine swap in the WatsonCrick double helix can be accommodated within the triple helix, albeit with a slight decrease in stability for the resulting triple helix [47]. The RNA sequence analysed in [45] forms a triple helix with 7 base triples at $\mathrm{pH} 4.3$, whereas the DNA triple helices containing single mismatches form stable structures at pH 5.6 [47]. Michael Yarus and colleagues have produced a 24-nucleotide self-aminoacylating ribozyme possessing only three conserved nucleotides [18] and this was subsequently truncated to a mere 5-nucleotide ribozyme able to aminoacylate a 4-nucleotide RNA substrate in trans [48]. This reaction suggests a possible mechanism for the specific recognition of the aminoacyl stem of tRNA or its hairpin without the requirement for strand-separation: as illustrated in Figure 6, a polypyrimidine stretch of the aminoacylating ribozyme could specifically recognize the operational RNA code nucleotides in the tRNA/hairpin aminoacyl stem through base-pair specific interaction with the purine-rich 5' strand at $\mathrm{pH}$ 4-5. Supporting this possibility, the analogous (5') strand of the aminoacyl stem of $E$. coli tRNA $^{\text {Gly(GCC) }}$ (we have previously proposed tRNA ${ }^{\text {Gly }}$ was the first tRNA to evolve [20]) contains the strikingly purine-rich sequence GCGGGAA [49]; a number of other tRNAs have a similarly purine-rich 5' strand [49]. Different purine-rich sequences embedded in the aminoacyl stems of

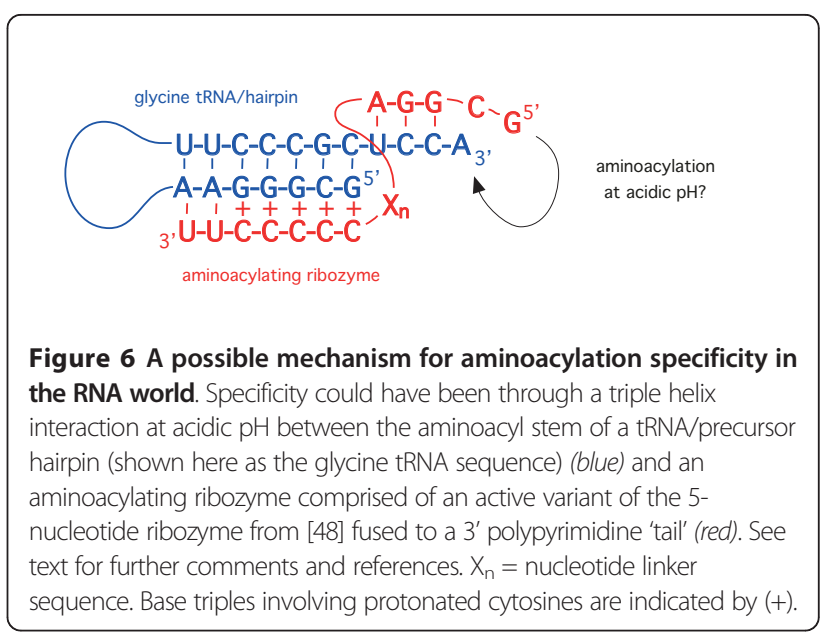

hairpins/tRNAs could have been recognized by complementary polypyrimidine sequence 'tails' of ribozymes able to catalyse the attachment of different amino acids. These purine-rich sequences may have been the forerunners of the operational RNA code, recognized today by protein aminoacyl-tRNA synthetases.

\section{Implications of the hypothesis \\ RNA world incompatible with alkaline deep-sea hydrothermal vent origin}

The major implication of our hypothesis is that it suggests the evolution of RNA is unlikely to have occurred in the vicinity of an alkaline deep-sea hydrothermal vent as has been proposed $[4,6,8,9]$, but rather took place within the acidic Hadean ocean itself (possibly in the vicinity of an acidic deep-sea hydrothermal vent or 'black smoker'), in an acidic volcanic lake [7], or comet pond [50]. While it is certainly possible that molecular evolution prior to the emergence of RNA could have occurred in the vicinity of an alkaline vent, it seems that in order for RNA to evolve, the proto-cell would have had to escape this alkaline environment. The argument from parsimony, however, would suggest that all early evolution took place in acidic conditions, with the energy required by the first life forms potentially provided by a protonmotive gradient across the proto-cell membrane [51,52], as the acidic environment interfaced with a slightly more alkaline interior (in fact, de Duve has made the observation that "the widespread use of protonmotive force for energy transduction throughout the living world today is explained as a legacy of a highly acidic prebiotic environment and may be viewed as a clue to the existence of such an environment" [53]). If life arose at high temperature, only the most stable RNA structures such as protonated GC-rich hairpins - would have been resistant to degradation and thus survived. It seems likely that life emerged as soon as it became physically possible for it to do so. 


\section{Alternative base-pairing schemes: evidence from modern tRNA secondary structure}

A second implication of our hypothesis concerns the ability of RNA to form non-standard base pairs at acidic $\mathrm{pH}$ (Engelhart and Hud have also suggested the possible importance in early evolution of alternative base pairings, such as purine-purine and pyrimidine-pyrimidine duplexes [54]). The ability of C-C $[37,43]$ and C-A [39-43] to form protonated base pairs at acidic $\mathrm{pH}$ suggests that standard base pairing may not have been an essential or exclusive requirement of the early RNA world. Error-prone replication of RNA in modern systems is due to the absence of error-correction mechanisms [55], and this was doubtless also the situation prior to the evolution of complex proteins. Replication ambiguity due to non-standard base pairing may have provided an additional means of increasing RNA sequence variation in the early RNA world.

We wondered whether the acidic intracellular $\mathrm{pH}$ that has been reported for some acidophilic archaebacteria might permit an increase in the number of $\mathrm{C}-\mathrm{C}$ and $\mathrm{C}$ A 'mismatches' in their cellular RNAs due to the potential ability of such mismatches to form stable protonated base pairs at acid $\mathrm{pH}$ (it has been shown that $\mathrm{C}-\mathrm{A}(+)$ pairs at $\mathrm{pH} \leq 5$ are of the same order of stability as G-C and A-U pairs at $\mathrm{pH} 7$ [40]). For our analysis we chose the tRNA gene-set (tRNome) from fourteen archaebacterial species: $i$ ) three acidophilic species reported to have an internal $\mathrm{pH} \leq 6$ : Thermoplasma acidophilum [56] with a reported internal pH of 6.2 [57], Ferroplasma acidarmanus [58,59] with a reported internal $\mathrm{pH}$ of $4.9 \pm 0.5$ [60], and Picrophilus torridus, the sister species of which (Picrophilus oshimae) has a reported internal pH of 4.6 [61]; ii) one acidophilic species, Sulfolobus solfataricus [62], the sister species of which (Sulfolobus acidocaldarius) has a reported internal $\mathrm{pH}$ of 6.5 [63]; and iii) ten non-acidophilic archaebacterial species for which the internal $\mathrm{pH}$ has not to our knowledge been reported: Aeropyrum pernix, Archaeoglobus fulgidus, Halobacterium sp., Methanobacterium thermoautotrophicum, Methanococcus jannaschii, Methanopyrus kandleri, Methanosarcina barkeri, Pyrobaculum aerophilum, Pyrococcus abyssi and Sulfolobus tokodaii. These sequences were taken from a database supplied by Marck and Grosjean ([64]; C. Marck, pers. commun.); and crosschecked against the sequences in the Lowe tRNA Genomic Database [59]. We manually inspected 20 base pairs in the four stems of the tRNA cloverleaf secondary structure that are almost exclusively standard G-C, A-U and G-U interactions. These 20 base pairs comprised the aminoacyl stem (7 base pairs), anticodon stem (5), T stem (5) and D stem (3). The fourth D stem base pair 13-22 was not used as it contains a high proportion of base pair mismatches in all known non- mitochondrial tRNAs. Our findings were as follows: $i$ ) Thermoplasma acidophilum (reported internal pH 6.2) has 2 C-A 'mismatches' (plus a T-T mismatch), Picrophilus torridus (internal $\mathrm{pH} \sim 4.6$ ) has $5 \mathrm{C}$-A mismatches (plus a T-T and an A-A mismatch), and Ferroplasma acidarmanus (reported internal pH $4.9 \pm 0.5$ ), has $10 \mathrm{C}$ A mismatches (plus a T-T mismatch) (interestingly, none of these species' tRNAs contains a C-C mismatch in the 20 examined base pairs). Of the remaining 11 species analyzed from (ii) and (iii), Methanosarcina barkeri had 2 C-A mismatches and only 2 others had a single $\mathrm{C}-\mathrm{A}$ or $\mathrm{C}-\mathrm{C}$ mismatch. Comparing the numbers of $\mathrm{C}-\mathrm{A}$ and $\mathrm{C}-\mathrm{C}$ mismatches in the tRNomes of the 3 species with an internal $\mathrm{pH} \leq 6$ with those in the remaining 11 species (with a reported or presumed internal $\mathrm{pH} \geq$ $6.5)$, gave a significance of $\mathrm{p}$-value $=0.003$ using the one-sided Wilcoxon Rank Sum (Mann-Whitney U) test [65], indicating a relationship between a reported acidic internal $\mathrm{pH}$ and the presence of C-A and C-C 'mismatches' in tRNA secondary structure (F. acidarmanus, which at ten has the highest number of such 'mismatches' of the sample group, could have a more acidic intracellular $\mathrm{pH}$ than has been reported [66]). One would predict that the C-A 'mismatches' in the tRNAs of $P$. torridus and F. acidarmanus are protonated, although definitive proof of this would require experimental confirmation. Nonetheless, our findings suggest that an acidic intracellular $\mathrm{pH}$ may have allowed for an increase in the number of protonatable C-A pairs in the tRNomes of acidophilic archaebacteria with an acidic internal pH. It would therefore appear feasible that such protonated base pairs might have played a structural role in an RNA world at acidic $\mathrm{pH}$.

\section{Conclusions}

We have presented evidence that an acidic chemical environment is most compatible with the evolution of an RNA world. Acidic pH stabilizes key intra- and intermolecular RNA bonds, including those important for the evolution of protein synthesis, and facilitates additional protonated base interactions so that the behaviour of RNA under these conditions would not be constrained by the standard rules of base pairing. The diversity of stabilizing bonds provides additional potential mechanisms for sustaining the RNA world and initiating an RNA-protein breakthrough. Such a hypothesis casts doubt on previous proposals of an origin of life in the vicinity of alkaline hydrothermal vents.

\section{Note added in proof}

Since submitting the manuscript, David Deamer has alerted us to two papers by his group that demonstrate nonenzymatic RNA synthesis [67] and nonenzymatic templated DNA replication [68] from non-activated 
monophosphate nucleotides at $\mathrm{pH} \sim 2-3$ in the presence of a lipid matrix undergoing repeated cycles of wetting/ drying. However, the formation of C-A and/or C-C base pairs was not reported for nonenzymatic templated DNA replication at acidic $\mathrm{pH}[68]$.

\section{Reviewers' comments}

\section{Referee 1: Eugene Koonin}

Bernhardt and Tate discuss at length the possibility that the RNA World evolved at mildly acidic pH in the vicinity of acidic hydrothermal vents or volcanic lakes, as opposed to alkaline vents under the Martin-Russell scenario. I believe that they have a good case given that higher stability of RNA under acidic conditions is textbook knowledge whereas recent experiments added multiple observations of acidic optima for ribozyme-catalyzed reactions. To me, this article reads more like a review than a typical hypothesis because the rather obvious idea that acidic conditions could be more conducive for the evolution of an RNA world than alkaline conditions has been aired repeatedly over years (eg, their Ref. 11). However, this does appear to be the first detailed article that is fully dedicated to the acidic RNA World scenario, and in that capacity the article should become a useful and welcome addition to the origin of life literature.

\section{Referee 2: Anthony Poole}

In this article, Bernhardt and Tate consider an important matter, often ignored in discussions of the plausibility of the RNA world hypothesis - the chemical environment most favourable to such a scenario. Based on an informative review of available biochemical literature, they argue that the RNA world, if it existed, would have been most favourable at acidic $\mathrm{pH}$. They also note that peptide bonds - but not DNA - are optimally stable at acidic $\mathrm{pH}$, suggesting that scenarios for early evolution where a physical environment is invoked should include consideration of this fact. The authors go on to argue that an acidic Hadean ocean, but not the more alkaline environments of Lost City, would be favourable to the emergence of an RNA world.

I think the authors are onto something here, but it would have been good to have seen some broader discussion on the possible environment. I am not sure that synthesis (as opposed to degradation) in the ocean is expected - if the authors believe it is, this is an important point that needs to be integrated into discussion. In this respect, I would be interested to hear the authors' thoughts on the recent proposal for pumice as a possible site for the origin of life [69]. This seems broadly compatible with the authors' suggestion, and has the advantage of not requiring the origin of life in an ocean environment where degradation might prevail over syntheses.

\section{Authors' response}

As implied in the manuscript, the authors consider the first step in the emergence of life to have been compartmentalization within lipid vesicles. This is in contrast to hypotheses invoking 'naked genes on the beach' - as proposed in Lathe's fast tidal cycling or PCR hypothesis $[70,71]$ - or those invoking inorganic compartments alone, such as iron sulfide bubbles $[4,6,8,9]$, but does not preclude catalytic mineral nanoparticles being entrapped within vesicles. Brasier's pumice hypothesis [69] invokes lipid vesicles held within pumice nanopores and is compatible with our favoured 'oil slick hypothesis' as proposed by Nilson [72], with life evolving beneath a skin of organic matter, endogenous or delivered by extraterrestrial means. Assembly of the first lipid vesicles could have occurred at the 'oil'-ocean interface, with the proton gradient between an acidic ocean and a more neutral vesicle interior providing a source of energy. A surface layer would have afforded the first life forms protection from UV radiation from the sun, in the absence of atmospheric oxygen and the resultant ozone layer. Pumice could have provided an absorption matrix for lipids within the organic material on the ocean surface. Wetting/drying cycles invoked for beached pumice - with the addition of a lipid matrix - even have a slight overlap with Lathe's fast tidal cycling/PCR hypothesis $[70,71]$. Brasier and colleagues [69] write that their floating pumice rafts would allow for transport between these two wet and dry environments.

I do overall think the case made by the authors is an important one, and deserving of further consideration, but I do wonder about one or two of the arguments. For instance, the statement in reference to the Järvinen paper [10] on p6 is a little surprising - here it is pointed out that phosphodiester bond hydrolysis of dinucleosides is lowest at $\mathrm{pH} 4-5$ at $90^{\circ} \mathrm{C}$, within the temperature range of the Hadean ocean. What worries me about this is that such temperatures do not seem particularly compatible with functioning RNA. Here the relevant property is not the conditions under which phosphodiester bond hydrolysis occurs but the conditions under which tertiary structure (and by proxy, RNA function) is stable. Given that tertiary structure is not known to be stable at such high temperatures, even in thermostable ribozymes [73], I suspect a much lower temperature would have been necessary for an RNA world. This might not be incompatible with the general conclusions drawn by the authors regarding an acidic environment for an RNA world - some more careful consideration on the relationship to temperature might be valuable here: specifically, how much does lowering $\mathrm{pH}$ improve tertiary structure stability of RNAs? 


\section{Authors' response}

As indicated by the reviewer, lower temperature conditions are not incompatible with our proposal of an acidic environment of the RNA world, and indeed RNA is stable at acid $\mathrm{pH}$ over a wide range of temperatures, with modest changes in $\mathrm{pH}$ for optimum stability (as shown by Kua and Bada [30], ribose, cytosine and the phosphodiester bond are most stable at 0 degrees celsius at $\mathrm{pH}$ 5.5). It is clear that the two main forces responsible for RNA secondary and tertiary structure, hydrogen bonding and Van der Waals (hydrophobic) interactions, would be diminished at high temperatures. Electrostatic interactions due to the formation of protonated base pairs [74] could increase tertiary structure stability at elevated temperatures, partly through interactions between protonated base pairs and the negatively charged phosphate backbone. Such an effect would be sequence-dependent. This would be similar to the increase in (hyper)thermophilic protein stability afforded by an increase in the number of charged surface residues [75].

Another case where a clearer argument on temperature could be made is in reference to ancestral reconstruction of thioredoxin enzymes, EF-Tu, and the discussion of protein enzymes from $A$. aceti that are thermostable and resistant to acidic $\mathrm{pH}$ (p11). These comparisons are weak, partly because such ancestral reconstruction is likely to be difficult, but mostly because, signal or no signal, they focus on protein, whereas the period the authors are looking at surely predates such proteins. In this respect, the work of Gouy and colleagues [76,77] may be more relevant; those authors looked at GC content of rRNA as a means of estimating the temperatures in which the Last Universal Common Ancestor existed. This work suggests a moderate temperature, though again - and this is relevant to both protein and RNA ancestral reconstruction - it is not possible to go further back than this hypothetical point, so, technical issues aside, it is difficult to say if this work sheds direct light on optimal temperature in an RNA world. Indeed, this point was made by Arrhenius and colleagues [78] in a letter that sought to correct a journalistic misinterpretation of Galtier and colleagues' work.

\section{Authors' response}

The authors completely agree with the thoughtful comments of the reviewer here, and this section has been removed from the final version of the manuscript.

I was intrigued by the discussion on $\mathrm{p} 17$ regarding the potential impact of an acidic cellular environment on protonated base pairs in tRNA from $A$. aceti, which is certainly an interesting line of enquiry. However, I was a bit surprised at how the paper ends - it seems rather abrupt, and lacks some concluding remarks or synthesis.
I think adding a final conclusions-type section would greatly enhance readability.

\section{Authors' response}

An analysis of protonated base pairs in the bacterium $A$. aceti in an earlier version of the manuscript has now been replaced by an analysis of their occurrence in 14 archaebacterial species (including two with a reportedly markedly acidic cytoplasm). A. aceti has no C-A (or CC) 'mismatches' in the 20 base pair positions of its tRNome, apart from a single universally conserved C1A73 base pair found in all bacterial initiator tRNAs ${ }^{\text {Met }}$ (sequence data obtained from J. Kappock, pers. commun.; [79]). This may be because the internal pH of $A$. aceti can vary between $\mathrm{pH}$ 3.9-5.8 [33], causing fluctuations in protonation (and base pair formation) of any $\mathrm{C}$ A (or C-C) mismatches present. Clearly this could cause problems for maintenance of the tRNA cloverleaf structure. A conclusion section has been added to the manuscript in response to this helpful suggestion.

Minor issues.

On p5 of the manuscript I think the reference numbering is out - reference 12 looks incorrect.

\section{Authors' response}

This reference has been corrected.

\section{Referee 3: Charles Carter, (nominated by David Ardell)}

This paper put me in touch with a wide range of stimulating ideas, and hence I find it worthy of publication. This recommendation comes despite having been put off intensely by the arrogant statement that the RNA world hypothesis "... has wide, if not unanimous, support". I, for one, have never subscribed to this view of the origin of life, and I am by no means alone. The RNA world hypothesis is driven almost entirely by the flow of data from very high technology combinatorial libraries, whose relationship to the prebiotic world is anything but worthy of "unanimous support". There are several serious problems associated with it, and I view it as little more than a popular fantasy.

\section{Authors' response}

We thank the reviewer for drawing our attention to a misleading sentence on the RNA world hypothesis. We have always acknowledged the diversity of views concerning

the validity of this concept. Unintentional phrasing implied almost universal acceptance in the original submission and has now been changed. Indeed, having attended the recent ISSOL 2011 conference in Montpellier (HSB), we are certainly aware that not everyone is of one mind in this matter!

That said, this paper has the virtue of reviewing clearly a number of cogent arguments that do not depend on high contemporary technology. Many of these arguments - the pH-dependent stability of the 
ribose-phosphate backbone - are obvious and certainly not original. Yet, they form the core of the "hypothesis" offered by the authors. The paper is, nonetheless, an interesting review of a diverse collection of the experimental observations of others.

There are several points to be considered by the authors:

1. The notion that the prebiotic earth was warm is by no means strongly supported by astrophysical data from the past decade, and reference 5 should be provided with a more recent accompanying one.

\section{Authors' response}

As stated above in our response to the second reviewer, thermophile conditions are not required for our hypothesis of an acidic RNA world. Nevertheless, we have taken the reviewer's advice and added two more recent references: [6,7]. Although there has been a move away from the concept of a hot prebiotic Earth, Sleep et al. (2011) state, "the origin of life under global thermophile conditions (e.g. [1]) remains a viable hypothesis, as does the origin under clement conditions during latter stages of this process (italics added)" [6].

2. The discussion of base-mispairing in acidophiles at the end of the paper is potentially quite interesting. However, it is presented anecdotally, without statistical significance testing, which appears to be feasible in this case.

\section{Authors' response}

We thank the reviewer for this suggestion, and as a result the analysis now includes a one-sided Wilcoxon Rank Sum statistical significance test [65], which shows a significant correlation between an acidic internal $\mathrm{pH}$ and the occurrence of $\mathrm{C}$-A mismatches. As an aside, it is interesting to note that the archaebacterial species analyzed have $\sim 45$ tRNAs in their tRNomes. With 20 base pairs per tRNA examined, this gives 900 base pair positions analyzed per species. Thus even in F. acidarmanus, which at 10 has the highest number of potentially protonatable C-A mismatches of the species examined, this represents only $\sim 1 \%$ of these base pairs. This is interesting from an evolutionary point of view, as it suggests that the move into an acidic environment occurred relatively recently in evolutionary time (if $F$. acidarmanus was an extant member of an ancient lineage that inhabited a similarly acidic niche, one might have expected the proportion of protonatable base pairs in the tRNome to be considerably higher). It has been suggested that $F$. acidarmanus's sister species $F$. acidophilum (which is similarly acidophilic and which has a high proportion $(\sim 86 \%)$ of metalloenzymes in its proteome [80]) is a relic from an ancestral acidic/high iron environment (unfortunately the $F$. acidophilum genome has not yet been sequenced). In light of the evidence presented here from $F$. acidarmanus, this would appear to be unlikely.
The relationship between an acidic internal $\mathrm{pH}$ and protonatable tRNA base pairs in eubacteria and eukaryotes may be slightly different to that found in archaebacteria: for example, Escherichia coli and Saccharomyces cerevisiae - both of which have a reported internal $\mathrm{pH} \sim 7[81,82]$ - each have $5 \mathrm{C}$ - A 'mismatches' in the same 20 base pairs of their tRNA genes (sequence data obtained from C. Marck, pers. commun.; [64]).

3. In as much as aminoacylation at low $\mathrm{pH}$ has "still to be verified" there is little scientific content to Figure 6 .

\section{Authors' response}

Although aminoacylation at $\mathrm{pH}$ 4-5 has not been verified experimentally, Michael Yarus has made the following comment regarding the $\mathrm{pH}$-dependence of the reaction rate of the original 5-nucleotide aminoacylating ribozyme reported in [48], a variant of which forms part of our proposed base-pair-specific aminoacylating ribozyme in Figure 6: "GUGGC is more or less log linear in $\mathrm{pH}$, so $10 \mathrm{x}$ slower at $\mathrm{pH} 6$ than 7" (M. Yarus, pers. commun.).

\section{List of abbreviations used}

5' UTR: 5' untranslated region; EF-Tu: elongation factor thermo unstable; NMR: nuclear magnetic resonance; PAGE: polyacrylamide gel electrophoresis; $p K_{\mathrm{a}}$ : acid dissociation constant; tRNome: complete set of tRNA genes in a genome.

\section{Acknowledgements}

Many thanks to Joe Kappock for critical reading of an early draft of this manuscript and for providing us with all kinds of helpful information (including references and tRNA sequences for A. aceti), Steven Benner for extremely helpful advice (including analysis of the literature) regarding intracellular pH measurement, Umesh Varshney for information regarding his development of acid PAGE analysis of aminoacyl-tRNA, David Deamer for alerting us to work he has done in this area, Caillan Crowe-McAuliffe for editing assistance, and the three reviewers whose comments have significantly improved the manuscript. Financial support was from the Marsden Fund of NZ (WPT). The research was conducted during tenure of a Health Sciences Career Development Award at the University of Otago (HSB).

\section{Authors' contributions}

HSB formulated and developed the hypothesis. WPT provided original ideas and played a mentoring role. Both authors discussed ideas and wrote the manuscript.

\section{Competing interests}

The authors declare that they have no competing interests.

Received: 31 August 2011 Accepted: 20 January 2012

Published: 20 January 2012

\section{References}

1. Pace NR: Origin of life-facing up to the physical setting. Cell 1991, 65:531-533.

2. Abramov O, Mojzsis SJ: Microbial habitability of the Hadean Earth during the late heavy bombardment. Nature 2009, 459:419-422.

3. Wilde SA, Valley JW, Peck WH, Graham CM: Evidence from detrital zircons for the existence of continental crust and oceans on the Earth $4.4 \mathrm{Gyr}$ ago. Nature 2001, 409:175-178.

4. Russell MJ, Hall AJ: The emergence of life from iron monosulphide bubbles at a submarine hydrothermal redox and $\mathrm{pH}$ front. $J \mathrm{Geo} / \mathrm{SoC}$ London 1997, 154:377-402. 
5. Morse JW, Mackenzie FT: Hadean ocean carbonate geochemistry. Aquat Geochem 1998, 4:301-319.

6. Sleep NH, Bird DK, Pope EC: Serpentinite and the dawn of life. Philos Trans R Soc Lond B Biol Sci 2011, 366:2857-2869.

7. Sleep NH: The Hadean-Archaean environment. Cold Spring Harb Perspect Biol 2010, 2:a002527.

8. Martin W, Russell MJ: On the origin of biochemistry at an alkaline hydrothermal vent. Philos Trans R Soc Lond B Biol Sci 2007, 362:1887-1925.

9. Martin W, Baross J, Kelley D, Russell MJ: Hydrothermal vents and the origin of life. Nat Rev Microbiol 2008, 6:805-814.

10. Järvinen $\mathrm{P}$, Oivanen $\mathrm{M}$, Lönnberg $\mathrm{H}$ : Interconversion and phosphoester hydrolysis of 2',5'- and 3',5'-dinucleoside monophosphates: kinetics and mechanisms. J Org Chem 1991, 56:5396-5401.

11. Jayasena VK, Gold $L$ : In vitro selection of self-cleaving RNAs with a low pH optimum. Proc Natl Acad Sci USA 1997, 94:10612-10617.

12. Burke DH, Hoffman DC: A novel acidophilic RNA motif that recognizes coenzyme A. Biochemistry 1998, 37:4653-4663.

13. Miyamoto $\mathrm{Y}$, Teramoto $\mathrm{N}$, Imanishi $\mathrm{Y}$, Ito $\mathrm{Y}$ : In vitro evolution and characterization of a ligase ribozyme adapted to acidic conditions: effect of further rounds of evolution. Biotechnol Bioeng 2005, 90:36-45.

14. Miyamoto $Y$, Teramoto $N$, Imanishi $Y$, Ito $Y$ : In vitro adaptation of a ligase ribozyme for activity under a low-pH condition. Biotechnol Bioeng 2001, 75:590-596.

15. Oivanen M, Kuusela S, Lönnberg H: Kinetics and mechanisms for the cleavage and isomerization of the phosphodiester bonds of RNA by Brønsted acids and bases. Chem Rev 1998, 98:961-990.

16. Kühne H, Joyce GF: Continuous in vitro evolution of ribozymes that operate under conditions of extreme pH. J Mol Evol 2003, 57:292-298.

17. Kumar RK, Yarus M: RNA-catalyzed amino acid activation. Biochemistry 2001, 40:6998-7004.

18. Chumachenko NV, Novikov $Y$, Yarus M: Rapid and simple ribozymic aminoacylation using three conserved nucleotides. J Am Chem Soc 2009, 131:5257-5263.

19. Di Giulio M: On the origin of the transfer RNA molecule. J Theor Biol 1992, 159:199-214

20. Bernhardt HS, Tate WP: Evidence from glycine transfer RNA of a frozen accident at the dawn of the genetic code. Biol Direct 2008, 3:53.

21. Bernhardt HS, Tate WP: The transition from noncoded to coded protein synthesis: did coding mRNAs arise from stability-enhancing binding partners to tRNA? Biol Direct 2010, 5:16

22. Wolfenden R: The mechanism of hydrolysis of amino acyl RNA. Biochemistry 1963, 2:1090-1092.

23. Schuber F, Pinck M: On the chemical reactivity of aminoacyl-tRNA ester bond. I. Influence of $\mathrm{pH}$ and nature of the acyl group on the rate of hydrolysis. Biochimie 1974, 56:383-390.

24. Varshney U, Lee CP, RajBhandary UL: Direct analysis of aminoacylation levels of tRNAs in vivo. Application to studying recognition of Escherichic coli initiator tRNA mutants by glutaminyl-tRNA synthetase. J Biol Chem 1991, 266:24712-24718.

25. Nissen P, Kjeldgaard M, Thirup S, Polekhina G, Reshetnikova L, Clark BF, Nyborg J: Crystal structure of the ternary complex of Phe-tRNAPhe, EFTu, and a GTP analog. Science 1995, 270:1464-1472.

26. Pascal $R$, Boiteau $L$, Commeyras A: From the prebiotic synthesis of aamino acids towards a primitive translation apparatus for the synthesis of peptides. Top Curr Chem 2005, 259:69-122.

27. Ferris JP, Usher DA: Origins of life. In Biochemistry. Edited by: Zubay G. Reading, MA: Addison-Wesley; 1983:1191-1241.

28. Freeland SJ, Knight RD, Landweber LF: Do proteins predate DNA? Science 1999, 286:690-692

29. Varani G: Exceptionally stable nucleic acid hairpins. Annu Rev Biophys Biomol Struct 1995, 24:379-404.

30. Kua J, Bada JL: Primordial ocean chemistry and its compatibility with the RNA world. Orig Life Evol Biosph 2011, (41):553-558

31. Perez-Jimenez R, Inglés-Prieto A, Zhao ZM, Sanchez-Romero I, AlegreCebollada J, Kosuri P, Garcia-Manyes S, Kappock TJ, Tanokura M, Holmgren A, Sanchez-Ruiz JM, Gaucher EA, Fernandez JM: Single-molecule paleoenzymology probes the chemistry of resurrected enzymes. Nat Struct Mol Biol 2011, 18:592-596.

32. Xu SZ, Sukumar P, Zeng F, Li J, Jairaman A, English A, Naylor J, Ciurtin C, Majeed Y, Milligan CJ, Bahnasi YM, Al-Shawaf E, Porter KE, Jiang LH,
Emery P, Sivaprasadarao A, Beech DJ: TRPC channel activation by extracellular thioredoxin. Nature 2008, 451:69-72.

33. Menzel $\mathrm{U}$, Gottschalk $\mathrm{G}$ : The internal $\mathrm{pH}$ of Acetobacterium wieringae and Acetobacter aceti during growth and production of acetic acid. Arch Microbiol 1985, 143:47-51.

34. Robertson MP, Joyce GF: The origins of the RNA world. In RNA Worlds. Edited by: Atkins JF, Gesteland RF, Cech TR. Cold Spring Harbor, NY: Cold Spring Harbour Press; 2010:21-42.

35. Inoue T, Joyce GF, Grzeskowiak K, Orgel LE, Brown JM, Reese CB: Templatedirected synthesis on the pentanucleotide CpCpGpCpC. J Mol Biol 1984, 178:669-676.

36. Acevedo OL, Orgel LE: Non-enzymatic transcription of an oligodeoxynucleotide 14 residues long. J Mol Biol 1987, 197:187-193.

37. Romby P, Westhof E, Moras D, Giegé R, Houssier C, Grosjean H: Studies on anticodon-anticodon interactions: hemi-protonation of cytosines induces self-pairing through the GCC anticodon of E. coli tRNA-Gly. J Biomol Struct Dyn 1986, 4:193-203.

38. Mariappan SV, Catasti P, Chen X, Ratliff R, Mazes RK, Bradbury EM, Gupta G: Solution structures of the individual single strands of the fragile $\times$ DNA triplets (GCC) $)_{n}(\mathrm{GGC})_{n}$. Nucleic Acids Res 1996, 24:784-792.

39. Durant PC, Davis DR: Stabilization of the anticodon stem-loop of tRNALys,3 by an A+-C base-pair and by pseudouridine. J Mol Biol 1999, 285:115-131.

40. Meroueh M, Chow CS: Thermodynamics of RNA hairpins containing single internal mismatches. Nucleic Acids Res 1999, 27:1118-1125.

41. Chirkova A, Erlacher MD, Clementi N, Zywicki M, Aigner M, Polacek N: The role of the universally conserved A2450-C2063 base pair in the ribosomal peptidyl transferase center. Nucleic Acids Res 2010, 38:4844-4855

42. Venditti V, Clos L, Niccolai N, Butcher SE: Minimum-energy path for a U6 RNA conformational change involving protonation, base-pair rearrangement and base flipping. J Mol Biol 2009, 391:894-905.

43. Bink HH, Hellendoorn $\mathrm{K}$, van der Meulen J, Pleij CW: Protonation of nonWatson-Crick base pairs and encapsidation of turnip yellow mosaic virus RNA. Proc Natl Acad Sci USA 2002, 99:13465-13470.

44. Schimmel P, Giegé R, Moras D, Yokoyama S: An operational RNA code for amino acids and possible relationship to genetic code. Proc Natl Acad SC USA 1993, 90:8763-8768.

45. Holland JA, Hoffman DW: Structural features and stability of an RNA triple helix in solution. Nucleic Acids Res 1996, 24:2841-2848.

46. Shefer $K$, Brown Y, Gorkovoy V, Nussbaum T, Ulyanov NB, Tzfati Y: A triple helix within a pseudoknot is a conserved and essential element of telomerase RNA. Mol Cell Biol 2007, 27:2130-2143.

47. Mergny JL, Sun JS, Rougée M, Montenay-Garestier T, Barcelo F, Chomilier J, Hélène C: Sequence specificity in triple-helix formation: experimental and theoretical studies of the effect of mismatches on triplex stability. Biochemistry 1991, 30:9791-9798.

48. Turk RM, Chumachenko NV, Yarus M: Multiple translational products from a five-nucleotide ribozyme. Proc Natl Acad Sci USA 2010, 107:4585-4589.

49. Jühling F, Mörl M, Hartmann RK, Sprinzl M, Stadler PF, Pütz J: tRNAdb 2009: compilation of tRNA sequences and tRNA genes. Nucleic Acids Res 2009, 37:D159-162.

50. Clark BC: Primeval procreative comet pond. Orig Life Evol Biosph 1988 18:209-238.

51. Chen IA, Szostak JW: Membrane growth can generate a transmembrane pH gradient in fatty acid vesicles. Proc Natl Acad Sci USA 2004, 101:7965-7970.

52. Namani T, Deamer DW: Stability of model membranes in extreme environments. Orig Life Evol Biosph 2008, 38:329-341.

53. de Duve C: Blueprint for a Cell: The Nature and Origin of Life Burlington, North Carolina: Neil Patterson Publishers, Carolina Biological Supply Company; 1991, 179.

54. Engelhart AE, Hud NV: Primitive genetic polymers. Cold Spring Harb Perspect Biol 2010, 2:a002196.

55. Domingo E, Escarmís C, Sevilla N, Moya A, Elena SF, Quer J, Novella IS, Holland JJ: Basic concepts in RNA virus evolution. FASEB J 1996, 10:859-864.

56. Ruepp A, Graml W, Santos-Martinez ML, Koretke KK, Volker C, Mewes HW, Frishman D, Stocker S, Lupas AN, Baumeister W: The genome sequence of the thermoacidophilic scavenger Thermoplasma acidophilum. Nature 2000, 407:508-513, GenBank: AL139299.1. 
57. Michels M, Bakker EP: Generation of a large, protonophore-sensitive proton motive force and $\mathrm{pH}$ difference in the acidophilic bacteria Thermoplasma acidophilum and Bacillus acidocaldarius. J Bacteriol 1985, 161:231-237.

58. Schneider KL, Pollard KS, Baertsch R, Pohl A, Lowe TM: The UCSC Archaeal Genome Browser. Nucleic Acids Res 2006, 34 Database: D407-D410, F. acidarmanus June 2005 draft (ferrAcid1) assembly; GenBank: AABC05000000.

59. Chan PP, Lowe TM: GtRNAdb: a database of transfer RNA genes detected in genomic sequence. Nucleic Acids Res 2009, 37 Database: D93-D97.

60. Macalady JL, Vestling MM, Baumler D, Boekelheide N, Kaspar CW, Banfield JF: Tetraether-linked membrane monolayers in Ferroplasma spp: a key to survival in acid. Extremophiles 2004, 8:411-419.

61. van de Vossenberg, Driessen AJ, Zillig W, Konings WN: Bioenergetics and cytoplasmic membrane stability of the extremely acidophilic, thermophilic archaeon Picrophilus oshimae. Extremophiles 1998, 2:67-74

62. She Q, Singh RK, Confalonieri F, Zivanovic Y, Allard G, Awayez MJ, ChanWeiher CC, Clausen IG, Curtis BA, De Moors A, Erauso G, Fletcher C, Gordon PM, Heikamp-de Jong I, Jeffries AC, Kozera CJ, Medina N, Peng X, Thi-Ngoc HP, Redder P, Schenk ME, Theriault C, Tolstrup N, Charlebois RL, Doolittle WF, Duguet M, Gaasterland T, Garrett RA, Ragan MA, Sensen CW, Van der Oost J: The complete genome of the crenarchaeon Sulfolobus solfataricus P2. Proc Natl Acad Sci USA 2001, 98:7835-7840, GenBank: AE006641.1.

63. Moll $\mathrm{R}$, Schäfer $\mathrm{G}$ : Chemiosmotic $\mathrm{H}^{+}$cycling across the plasma membrane of the thermoacidophilic archaebacterium Sulfolobus acidocaldarius. FEBS Letters 1988, 232:359-363.

64. Marck C, Grosjean H: tRNomics: analysis of tRNA genes from 50 genomes of Eukarya, Archaea, and Bacteria reveals anticodon-sparing strategies and domain-specific features. RNA 2002, 8:1189-1232.

65. Mann HB, Whitney DR: On a test of whether one of two random variables is stochastically larger than the other. Ann Math Statist 1947, 18:50-60.

66. Golyshina OV, Golyshin PN, Timmis KN, Ferrer M: The 'pH optimum anomaly' of intracellular enzymes of Ferroplasma acidiphilum. Environ Microbiol 2006, 8:416-425.

67. Rajamani S, Vlassov A, Benner S, Coombs A, Olasagasti F, Deamer D: Lipidassisted synthesis of RNA-like polymers from mononucleotides. Orig Life Evol Biosph 2008, 38:57-74.

68. Olasagasti F, Kim HJ, Pourmand N, Deamer DW: Non-enzymatic transfer of sequence information under plausible prebiotic conditions. Biochimie 2011, 93:556-561.

69. Brasier MD, Matthewman R, McMahon S, Wacey D: Pumice as a remarkable substrate for the origin of life. Astrobiology 2011, 11:725-735.

70. Lathe R: Fast tidal cycling and the origin of life. Icarus 2003, 168:18-22.

71. Lathe R: Tidal chain reaction and the origin of replicating biopolymers. Int J Astrobiol 2005, 4:19-31.

72. Nilson FP: Possible impact of a primordial oil slick on atmospheric and chemical evolution. Orig Life Evol Biosph 2002, 32:247-253.

73. Guo F, Cech TR: Evolution of Tetrahymena ribozyme mutants with increased structural stability. Nat Struct Biol 2002, 9:855-861.

74. Rhee S, Han Z, Liu K, Miles HT, Davies DR: Structure of a triple helical DNA with a triplex-duplex junction. Biochemistry 1999, 38:16810-16815.

75. Strickler SS, Gribenko AV, Gribenko AV, Keiffer TR, Tomlinson J, Reihle T, Loladze W, Makhatadze Gl: Protein stability and surface electrostatics: a charged relationship. Biochemistry 2006, 45:2761-2766.

76. Galtier N, Tourasse N, Gouy M: A nonhyperthermophilic common ancestor to extant life forms. Science 1999, 283:220-221.

77. Boussau B, Blanquart S, Necsulea A, Lartillot N, Gouy M: Parallel adaptations to high temperatures in the Archaean eon. Nature 2008, 456:942-945.

78. Arrhenius G, Bada JL, Joyce GF, Lazcano A, Miller S, Orgel LE: Origin and ancestor: separate environments. Science 1999, 283:792.

79. Francois JA, Kappock TJ: Alanine racemase from the acidophile Acetobacter aceti. Protein Expr Purif 2007, 51:39-48, [http://www.ncbi.nlm. nih.gov/pubmed/16843006,http://dx.doi.org/10.1016/j.pep.2006.05.016]

80. Ferrer M, Golyshina OV, Beloqui A, Golyshin PN, Timmis KN: The cellular machinery of Ferroplasma acidiphilum is iron-protein-dominated. Nature 2007, 445:91-94.

81. Hickey EW, Hirshfield IN: Low-pH-induced effects on patterns of protein synthesis and on internal $\mathrm{pH}$ in Escherichia coli and Salmonella typhimurium. Appl Environ Microbiol 1990, 56:1038-1045.

82. Dombek KM, Ingram LO: Ethanol production during batch fermentation with Saccharomyces cerevisiae: changes in glycolytic enzymes and internal pH. Appl Environ Microbiol 1987, 53:1286-1291. doi:10.1186/1745-6150-7-4

Cite this article as: Bernhardt and Tate: Primordial soup or vinaigrette: did the RNA world evolve at acidic pH? Biology Direct 2012 7:4.

\section{Submit your next manuscript to BioMed Central and take full advantage of:}

- Convenient online submission

- Thorough peer review

- No space constraints or color figure charges

- Immediate publication on acceptance

- Inclusion in PubMed, CAS, Scopus and Google Scholar

- Research which is freely available for redistribution

Submit your manuscript at www.biomedcentral.com/submit
Ciomed Central 